rev.relac.int.estrateg.segur.11(1):219-238,2016

\title{
UN EJÉRCITO PARA LA PAZ. LAS BASES PARA EL CAMBIO DOCTRINARIO EN EL EJÉRCITO DE CHILE (2002-2006)*
}

\author{
Felipe Andrés Seguel Rojas ${ }^{* *}$
}

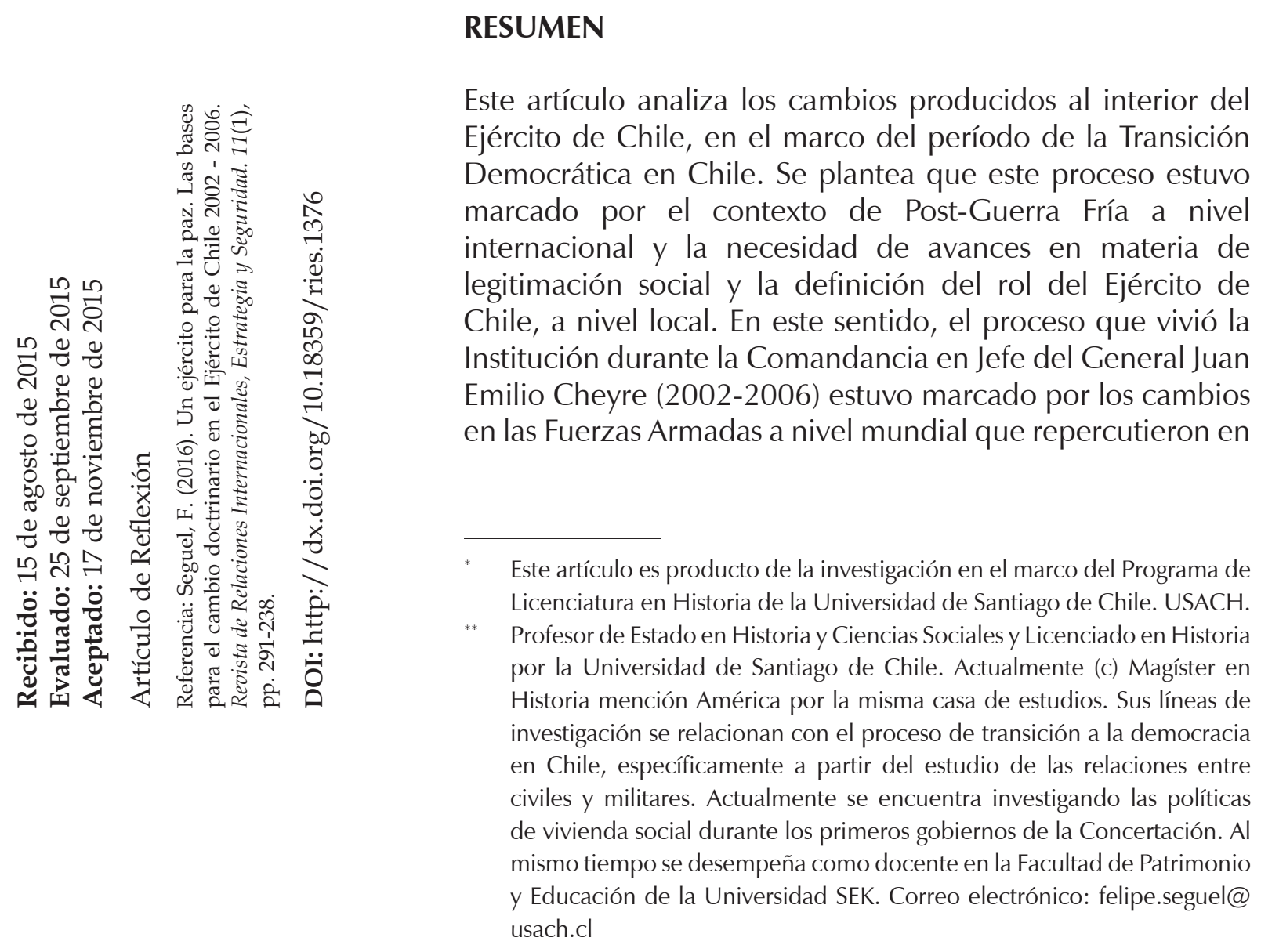


la conformación de nuevos conceptos rectores de su profesionalismo. Este cambio le entregó al Ejército chileno nuevas directrices para reorganizar su acción profesional dentro del contexto nacional y para su reinserción internacional conforme la política de Defensa.

Palabras clave: Doctrina, Fuerzas Armadas, Posguerra Fría, Profesionalismo, Transición Democrática.

\title{
AN ARMY FOR PEACE: THE BASES OF THE DOCTRINAIRE CHANGE IN THE CHILEAN ARMY (2002-2006)
}

\begin{abstract}
This article analyzes the changes within the army of Chile, within the period of democratic transition. It is proposed that this process was marked by the international context and the need for progress on social legitimacy and defining the role of the Chilean Army in the context of Post-Cold War. In this sense, the process experienced by the Institution for the Commander in Chief of General Juan Emilio Cheyre (2002-2006) was marked by changes in the armed forces worldwide that affected the formation of new guiding concepts of professionalism. This change gave the Chilean Army new guidelines to reorganize their professional action within the national context and for international reintegration as defense policy.
\end{abstract}

Keywords: Armed Forces; Doctrine; Post-Cold War; Professionalism; Democratic Transition.

\section{UM EXÉRCITO PARA A PAZ: AS BASES DO CAMBIO DOCTRINARIO NO EXÉRCITO DO CHILE (2002-2006)}

\section{RESUMO}

Este artigo analisa os câmbios produzidos ao interior do Exército do Chile, no marco de período da Transição democrática no Chile. Planteia-se que este processo estive marcado pelo contexto da Pós-Guerra Fria a nível internacional e a necessidade de avanços em matéria de legitimação social e a definiçã̃o do rol do exército do Chile, a nível local. Neste sentido, o processo que viveu a Instituição durante a comandância-em-chefe do General Juan Emilio Cheyre (2002 2006) estive marcado pelos câmbios nas forças armadas a nível mundial que repercutiram na conformação de novos conceitos reitores de seu profissionalismo. Este cambio entregou-lhe ao exército chileno novas instruções para reorganizar sua ação profissional, dentro do contexto nacional e para sua inserção conforme a política de defensa.

Palavras - Chave: Forças Armadas, Doutrina; Pós-Guerra Fría; Profissionalismo; Transição Democrática. 


\section{INTRODUCCIÓN}

Las transformaciones producidas a nivel internacional repercutieron en el Ejército chileno desde el comienzo de la transición democrática en Chile, pues a principios de la década de los noventa se discutió en todo el mundo el cambio de funciones respecto de las Fuerzas Armadas (FF.AA.) y sus nuevos objetivos. El abandono de la bipolaridad en política internacional con el término de la Guerra Fría vino a configurar un nuevo orden global determinado por el acuerdo tácito respecto del modelo neoliberal de desarrollo y la democracia como forma de gobierno. Estas transformaciones repercutieron en la constatación de nuevas amenazas para los ejércitos del mundo y por consiguiente una redefinición de los objetivos y conceptos articuladores del profesionalismo. Este proceso fue, igualmente, profundo en el Ejército de Chile, debiendo enfrentar quiebres en sus concepciones profesionales que redefinieron doctrinariamente sus funciones al interior de la sociedad y con respecto al sistema político. Este proceso comenzó bajo la comandancia en Jefe del general Juan Emilio Cheyre, pues el contexto nacional y el perfil de sus antecesores repercutieron negativamente, dificultando la integración de la institución castrense en el ámbito internacional y a sus nuevas funciones. De esta manera, el nuevo concepto de profesionalismo fue uno de los ejes de la doctrina Cheyre, que articularon junto con el pensamiento político y la organización de la fuerza, las bases para el proceso de despinochetización ${ }^{1}$. Debe recalcarse, sin embargo, que esta redefinición estuvo marcada por un escenario internacional de cambios y readecuaciones de las FF.AA., que nutrió y sustentó, los cambios en el Ejército de Chile.

Los estudios existentes respecto a esta temática han sido de dos tipos. El primero de ellos apunta a un nuevo ordenamiento en torno a la globalización, que determinó la agenda internacional en función de nuevos ordenamientos multilaterales, pues el contexto de Posguerra Fría habría cambiado las formas de relacionarse en el ámbito internacional (Massardo, 2008; Castells, 2006; Rojo, 2006). La segunda dimensión apunta al impacto de dicho ordenamiento en las Fuerzas Armadas a nivel de la redefinición de amenazas, objetivos y estrategias para el mantenimiento de sus actividades en la sociedad nacional e internacional, este contexto empujó a las instituciones castrenses a transformar sus estructuras y entrenamientos (Kuhlmann \& Callaghan, 2004).

Las interrogantes que atraviesan este artículo se refieren a cuáles fueron las bases conceptuales que posibilitaron al Ejército de Chile avanzar en una nueva definición de profesionalismo ¿En qué sentido el escenario internacional ayudó a que el Ejército de Chile iniciara un proceso de despinochetización basado en nuevos conceptos emanados de aquel debate? Por último, ¿de qué manera se reflejó el nuevo profesionalismo impulsado en el Ejército dentro el contexto nacional?

1. Se refiere al abandono de la herencia doctrinaria de la Comandancia en Jefe del General Augusto Pinochet durante el período (1973-1998). 
Este artículo tiene como objetivo analizar la redefición de las FF.AA., específicamente el Ejército de Chile, durante el período de transición democrática en Chile. Así como también, las concepciones de profesionalismo al interior del Ejército durante el período de la comandancia en Jefe del general Juan Emilio Cheyre, se intentará analizar las características que este profesionalismo le entregó al Ejército para sustentar este proceso de cambio alcanzando legitimidad social en el contexto nacional.

Entendemos este proceso que estuvo marcado por los cambios en las FF.AA. a nivel mundial que repercutieron en la conformación de nuevos conceptos rectores de su profesionalismo. Este cambio le entregó al Ejército chileno nuevas directrices para reorganizar su acción profesional dentro del contexto nacional y para su reinserción internacional conforme la Política de Defensa.

Este artículo se encuentra dividido en dos secciones. La primera de ellas, recopilará el debate internacional respecto de las funciones de las Fuerzas Armadas en la Posguerra Fría. La segunda, se avocará al estudio de los avances institucionales en materia del nuevo concepto de profesionalismo que se incorporó durante el periodo del general Juan Emilio Cheyre.

\section{El paradigma del siglo XXI. El mundo y los militares después de la guerra fría en el debate teórico}

El desarrollo histórico del siglo XX estuvo marcado por un protagonismo inapelable de las FF.AA. en los grandes cambios estructurales que se dieron cita en todas partes del mundo. Tal fue el protagonismo en los golpes de Estado latinoamericanos, en dónde la decisión estratégica nace de las lógicas de los uniformados. Siendo esto así, resulta problemático pensar en la autonomía de las FF.AA. y en su capacidad para influir un gobierno civil. Intentaremos establecer cómo debe ser la relación entre los militares y la sociedad civil en este nuevo escenario, y cómo se crea una confiable subordinación de las de las instituciones castrenses al poder civil, tomando en cuenta los altos niveles de autonomía heredados del régimen cívico-militar encabezado por el general Augusto Pinochet. El concepto de profesionalismo castrense se relaciona con estas temáticas y busca encuadrar la función de las FF.AA. y del Ejército de Chile en este caso, con la sociedad civil y los gobierno civiles.

El estudio desde las ciencias sociales, especialmente las ciencias políticas, respecto de este problema, ha coincidido que el cambio de contexto político internacional le ha entregado a las FF.AA. nuevos elementos para configurar su profesionalismo, toda vez que han definido los cambios dentro de estrategias militares a partir de cuatro elementos claves: nuevas amenazas, nuevas funciones, nuevos aportes al desarrollo nacional y un escenario internacional apto para la cooperación entre los ejércitos. Estos aportes, emanados desde el estudio de la sociología militar, proveen conocimientos y estrategias acerca de cómo se puede llevar a cabo tareas ya tradicionales de las FF.AA. y obtener de ello buenos resultados y, además, aportar un conocimiento acerca de las nuevas demandas y roles de las instituciones castrenses en la actualidad (Gutiérrez, 2002). 
La pertinencia de los estudios de caso y los análisis y miradas respecto a las FF.AA. son una herramienta útil, lo que demuestra primero un acercamiento del mundo civil a los temas que antiguamente eran monopolizados por los militares y una valoración por parte de los uniformados a dichos estudios, que proporcionan visiones que aportan para la formación de programas raltivos para preparar oficiales más capacitados que comprenden la la naturaleza de los problemas de la sociedad civil.

Estas transformaciones se sustentaron sobre la base de la tradición militar, por lo cual no significaría el abandono de los principios regidores de las instituciones castrenses como la defensa de la soberanía, la integridad territorial y la administración de la violencia. En efecto, la función que originalmente se le ha asignado a las FF.AA. en las sociedades modernas es el monopolio de los medios que ejercen la fuerza, es decir, las armas, las cuales están bajo el alero del Estado. Los individuos que componen los ejércitos se caracterizan por la pericia en el control de los métodos de las armas, lo que demuestra la característica esencial de la destreza militar (Gutiérrez, 2002). Se trata de individuos expertos en ejercer la fuerza, controlar mediante ella una situación desbocada y mantener un dominio exclusivo de los medios para ejercer violencia, propiciada por el Estado.

A principios de la década de los noventa, los estudios respecto de las nuevas funciones de los uniformados se realizaron principalmente en Europa. Después del fin de la Guerra Fría, los países del viejo continente, tanto del este como del occidente, enfrentaron la misma interrogante, cómo responderían sus organizaciones militares y las de sus vecinos a los cambios en las relaciones internacionales que afectan a sus economías, a sus percepciones de las amenazas, ya sean regionales o globalizadas, y al control de la seguridad entre las naciones (Kuhlmann \& Callaghan, 2004). Este proceso provocó que los uniformados enfrentaran un nuevo desafío de legitimidad respecto de sus roles en la sociedad actual, basado en nuevas concepciones de amenazas, tales como, contaminación ambiental, conflicto étnico, crecimiento de la población, entre otros (Kuhlmann \& Callaghan, 2004). Dentro de este nuevo escenario, la búsqueda de posicionamiento respecto de las instituciones castrenses en el ámbito internacional demandó transformaciones más profundas al interior de la organización de la fuerza y su doctrina. De esta manera, al analizar los problemas de seguridad y sus soluciones, necesariamente se debía ampliar la capacidad de acción de los uniformados y su discurso, abandonando el enfoque militar más limitado, propio de las características de la Guerra Fría. Por esta razón, el proceso de modernización del Ejército chileno emprendido por el general Augusto Pinochet, militar hijo de la Guerra Fría, no encontró en su liderazgo el sustento necesario para lograr sus objetivos y metas.

El contexto de Posguerra Fría, provocó el desvanecimiento de las amenazas de una confrontación por un mundo bipolar con el correr de la década de los noventa. Ello incidió en que las nuevas funciones se orientaron a la generación de confianzas en las instancias multilaterales, por lo que las misiones de paz y la conformación de ejércitos multinacionales adquirieron cada vez mayores niveles de legitimación social. A partir de ello, la capacidad de las instituciones 
castrenses se ha organizado en función de la tecnificación de sus funciones, es decir, en la búsqueda de mayores niveles de organización para el logro de sus objetivos con eficacia. En este sentido, las FF.AA. buscaron modernizarse para lograr una mayor adaptación al dinámico contexto. En este escenario, los ejércitos de Europa realizaron un proceso de relegitimación social, que complementaron sus modernizaciones.

Los cambios que se introdujeron en las FF.AA. respondieron también a las demandas de la sociedad civil de cada país, complementando sus transformaciones institucionales a partir de una nueva estructura de relaciones con los civiles.

+ Las organizaciones militares enfrentan cambios que emanan tanto del entorno internacional como de las estructuras sociales locales. Adaptarse a ambas fuentes de cambio implica necesariamente la reconstrucción de las estructuras organizacionales, equipamiento, la doctrina, y el ethos cultural heredado del pasado. (Kuhlmann \& Callaghan, 2004)

Los cambios en los contextos internacionales y nacionales, empujaron a las FF.AA. a realizar cambios significativos, para la alcanzar mayores niveles de eficacia en la ejecución de sus labores institucionales. Los nuevos tiempos llevaron a los uniformados a establecer una redefinición de los nuevos riesgos, las amenazas que antes se definieron en función del enfrentamiento bipolar debieron ser repensadas. La globalización implicó una mayor extensión de la uniformidad dentro de los ámbitos político, económico y social, generando el desafío de mantener la estructura del Estado-nación frente al surgimiento de las instancias multinacionales. De este modo, resultó una necesidad para los ejércitos el aportar al desarrollo nacional, frente a un escenario que debilitó el concepto de soberanía del Estado y la posibilidad de un conflicto armado. Frente a un contexto del mundo multicéntrico, los conceptos de seguridad nacional debieron redefinirse en función de una mayor integración a las instancias multilaterales que el escenario internacional ofrecía (Kuhlmann \& Callaghan, 2004).

En definitiva, las FF.AA. son instrumentos constitutivos de legítima defensa, pero enfrentaron un debilitamiento en su justificación técnica y moral para sólo promover intereses nacionales y proyectarlos en el escenario internacional. Las FF.AA. debieron redefinirse en función de la creación y mantención de la paz, basado en las definiciones de las instancias multilaterales (Kuhlmann \& Callaghan, 2004). El cambio que se produce en el escenario internacional, influyó en las definiciones de las instituciones armadas en el mundo, logrando un cambio más profundo en la percepción de los soldados:

El proceso de fondo, que cambia la política de seguridad internacional y la organización de las Fuerzas Armadas, está marcado por la globalización y por otras tendencias que se caracterizan por la integración y el multinacionalismo... Las Fuerzas Armadas se encuentran "multinacionalizadas", el resultado interino de este proceso es el soldado cuya moral y lealtad profesional se encuentran centradas en valores e ideas civiles, tales como la democracia y la libertad. (Kuhlmann y Callaghan, 2004) 
Los principios castrenses, como disciplina, cumplimiento del deber y tradición militar se mantienen, pero se modifica la capacidad profesional de los uniformados para cumplir con los objetivos que persiguen en el nuevo escenario internacional.

Mencionemos el proceso de transformación que enfrentó el Ejército alemán con posterioridad a la Segunda Guerra Mundial y que reestructuró las fuerzas durante la Posguerra Fría. La nueva orgánización de las FF.AA. alemanas se estructuró bajo el concepto de Bundeswehr, que establece que la organización de dichas instituciones responderá al mando civil, y que mediante la educación cívica y la participación, logró desarrollar la concepción de "ciudadano con uniforme" que permitió integrar a las instituciones castrenses a un contexto democrático (Kuhlmann \& Callaghan, 2004). Esta transformación respondió a las exigencias de subordinación al poder civil que demandaba la sociedad alemana, así la Bundeswehr respondía directamente al poder de un ministro civil y era responsabilidad de las autoridades civiles proporcionarles los elementos doctrinarios y prácticos para su desarrollo institucional. De esta forma, los soldados alemanes no practicaban la obediencia ciega sino que cumplían las órdenes porque estaban convencidos que eran necesarias (Kuhlmann \& Callaghan, 2004), ya que la Constitución alemana no realizó diferencias entre los derechos fundamentales entre los civiles y los uniformados.

Las transformaciones de las instituciones armadas europeas crearon nuevos objetivos. El Libro de Defensa de los alemanes de 1994, proclamó a sus FF.AA. como una institución destinada a salvaguardar la paz, trabajar para la unidad europea, insertarse en un sistema de seguridad colectiva y con capacidad para solucionar sus conflictos por la vía pacífica (Kuhlmann \& Callaghan, 2004). La capacidad de las FF.AA. alemanas de redefinir su papel en el escenario europeo provino, por una parte, de una política de defensa que se instauró desde las autoridades civiles, como también fue fruto del nuevo escenario europeo y mundial. Coherente con lo anterior, a sus objetivos de proteger a los ciudadanos alemanes y la integridad territorial, se sumó colaborar activamente en la estabilidad europea, servir a la paz mundial y la seguridad internacional en función de la carta de la ONU y apoyar a la población en desastres naturales y misiones de paz.

La sociedad rusa y los militares en el inicio del nuevo siglo no escaparon a las tendencias de las instituciones castrenses del resto de Europa. La reestructuración organizacional del ejército ruso enfrentó un proceso en el que se conjugan sus nuevas misiones, el legado de la antigua URSS, la identificación de la sociedad civil con los símbolos del ejército rojo y, de forma contradictoria, una escasa valoración de la sociedad civil a la profesión militar (Kuhlmann \& Callaghan, 2004) debido a las bajas remuneraciones de los soldados. Desde la caída de la URSS, el ejército ruso comenzó su reestructuración en función de nuevos objetivos institucionales, dónde se destacó que las FF.AA. rusas evitarían el conflicto, buscarían mantener la paz, hacer la paz y dar cumplimiento a las misiones comunitarias dentro del contexto de la ONU (Kuhlmann \& Callaghan, 2004). En este proceso, los nuevos objetivos son parte importante de la organización del ejército ruso, para quienes estar subordinados al poder civil constituyó la principal carta para la reinserción internacional. 
En resumen, podemos establecer que en la sociedad europea de la década de los noventa, se realizó un debate acerca del papel de las FF.AA. en el nuevo contexto, generándose nuevos conceptos para definir dichas funciones. El apoyo explícito que realizaron los ejércitos a la mantención de la paz y la estabilidad internacional, se constituyeron en las nuevas misiones para las FF.AA. en general. Esto implicó enfrentar el rediseño de sus fuerzas para alcanzar la eficacia al momento de hacer operativos los nacientes conceptos.

A partir de lo anterior se planteó que uno de los aspectos centrales de las relaciones cívicomilitares es que las instituciones castrenses son organizaciones que poseen "las dos caras del dios Jano". Por una parte, deben responder al contexto estratégico, construyendo organizaciones militarmente efectivas y, por otra parte, sobre todo en las sociedades democráticas, deben garantizar que las instituciones armadas respondan a los valores sociales más amplios y, por los tanto, a la sociedad que los financia, ya que sin su apoyo no es mucho lo que podrían hacer (Kuhlmann \& Callaghan, 2004). Para este periodo, las instituciones armadas se transformaron en función de las nuevas demandas de las sociedades civiles democráticas y el escenario de Posguerra Fría, proceso que influyó a todas las instituciones castrenses de Europa y del mundo.

En función de lo anterior, "las dos caras del dios Jano" se expresan en tres aspectos. El primero de ellos tiene relación con la diplomacia, donde las relaciones políticas, económicas y sociales del país, sustentan los procesos estratégicos, ya que la globalización redefinió las políticas estatales de Defensa, de organización de la fuerza y las relaciones cívico-militares. En este sentido, la formulación de las políticas internacional de los países se definió en función de la inserción de los Estados a este nuevo ordenamiento internacional. El segundo contexto es el nacional interno, dónde los factores políticos, económicos y sociales, influyen en las definiciones de amenazas y orientaciones doctrinarias, siendo para los militares el lugar dónde adquieren los valores de identidad y pertenencia. Por último, la relación de las instituciones castrenses con la historia reciente de los países, a partir de la cual se configuran las demandas de la sociedad civil y el diseño de las políticas de defensa para que dichas instituciones logren mayores niveles de legitimación social (Kuhlmann \& Callaghan, 2004). El peso de la historia influye en la forma en que las instituciones armadas se reconfiguran para enfrentar el nuevo escenario internacional y nacional. Para el caso europeo resultó completamente acertada la estrategia de impulsar misiones de paz y redefinir los ejércitos en función de identidades colectivas multinacionales, pues le dieron sentido a la función militar en el contexto de Posguerra Fría.

Como efecto de estos procesos se revitalizó el debate respecto del profesionalismo castrense. Dentro de las investigaciones acerca del valor de la profesionalización de las instituciones castrenses existen diversas interpretaciones. Algunas de ellas con posturas más próximas a los sectores armados y otras con mayor tendencia a rescatar la interacción con el poder civil. Es de esta manera, como podemos evidenciar la presencia de dos tendencias claramente definidas. La primera de ellas es aquella que coloca su atención principalmente en el uso de la fuerza militar como elemento central del estudio. Dentro de esta corriente, podemos encontrar a John Hackett el que interpretó la profesión militar en términos de "la aplicación ordenada de 
la fuerza a la solución de un problema social" (Hackett, 1983, p.45). Esta definición encierra la concepción instrumental de las FF.AA., en el sentido que el nivel de profesionalización depende de la eficiencia en la actitud represora de los organismos armados. Dentro de esta misma tendencia Harold Lasswell planteó que la profesionalización está relacionada con "la administración efectiva de la violencia" (Lasswell, 1947, p.32), mientras que Charles Moskos define la profesionalización de las FF.AA. como: "su experto dominio sobre la violencia mortífera, un sentimiento de identidad corporativo y una responsabilidad fundamental con respecto a una unidad política más amplia" (Gutiérrez, 2002, p.23).

Otro de los enfoques que se construyen resalta la naturaleza intrínseca de los soldados, en cuanto a su vocación por el bienestar de la sociedad. Encontramos en este enfoque el concepto del oficial chileno Herman Oehling, quién planteó: "profesión, arriesgada y técnica, que precisa de una dedicación completa a ideas y valores superiores, que exige una vocación apropiada y es capaz del sacrificio final, lo que exige vivir sujetos y con arreglo a un rígido código de honor" (Oehling, 1977, p.15). Este tipo de construcciones conceptuales destacan la dimensión axiológica de los uniformados y los sitúa en un escalón moral más alto que el resto de la sociedad. Dentro de esta tendencia, encontramos también el trabajo de Emilio Romero Salgado, quien postula que: "la profesión militar consiste en aceptar una fe y prometer una entrega perfecta y apasionada de todo lo mejor que hay en los miembros de la milicia al servicio de esos valores sagrados que no deben perecer- que forman en su conjunto la Patria-, y no para vivir de ella sino para que ellos subsistan" (Romero, 1962, p.165). De este tipo de definiciones podemos constatar la mirada a los valores que encierran la vida militar y que están en directa conexión con los enfoques de los sectores más cercanos al mundo castrense y más conservadores respecto de su rol.

Las tendencias actuales en el estudio de las relaciones cívico militares adoptaron el principio de que las diferencias entre la sociedad civil y los militares se han ido atenuando con el correr de los años, atendiendo a razones de cambios sociales y tecnológicos que habrían mutado la relación entre ambos mundos (Gutiérrez, 2002). Justificando la creciente interacción entre los mundos militares y civiles que hacen que los conceptos de profesionalismo cambien.

Los referentes más importantes dentro de esta tendencia son Morris Janowitz y Samuel Huntington, que han construido importantes estudios acerca de las relaciones cívico-militares. Para Huntington, las características más importantes de la profesión militar son la experticia, el corporativismo y la responsabilidad. Para Janowitz, estos elementos son importantes, pero agrega a ellos otros elementos relacionados con la educación impartida en centros de preparación de instituciones castrenses, la identidad grupal, la ética y el expertizaje.

Estos estudios han centrado su análisis en la función política de las instituciones castrenses como un tema relevante dentro del debate del profesionalismo. Para Huntington las FF.AA. deben ser políticamente neutras, alejadas de la sociedad y centrada solamente en la preocupación por obtener un triunfo eficaz y sin mayores problemas frente a sus enemigos. Por el contrario, 
Janowitz propone que las instituciones armadas deben ser subordinadas al poder civil a través de la ley, la tradición y el respeto por los valores que representan las instituciones civiles. Esta es una visión más pragmática de la relación militar y política (Huntington, 1995; Janowitz, 1960).

El concepto de Morris Janowitz le otorga una importancia enorme a las nuevas misiones del ejército en cuanto a formación de oficiales con conocimiento y destrezas en temas no sólo de la carrera militar sino también del ámbito civil pues no existe ninguna incompatibilidad entre los valores de los militares con los valores que construyen los civiles, más aún percibe como un elemento importante, la relación militar integrada con la sociedad civil. Para Janowitz mientras más integradas estén las FF.AA. con la sociedad mejor control por parte del poder civil se obtiene y una mejor respuesta por parte de los uniformados, configurando la antigua función del "guerrero heroico" que pasa a ser un elemento de la dirección administrativa de los Estados, pero bajo el poder civil (Janowitz, 1960).

Los estudios relacionados con el profesionalismo militar han dado cuenta de los cambios respecto del escenario de Posguerra Fría y, por ende, del rol social de las instituciones castrenses en el contexto nacional. Las antiguas atribuciones que tenían los uniformados se redefinieron en función de una mayor legitimidad social y funcionalidad para los objetivos de la política de la defensa.

Por último, uno de los factores que se empezó a desarrollar en la década de los noventa en los contextos europeos principalmente, fueron las medidas de confianza mutua entre los países y sus ejércitos. En este sentido, como lo plantea el general Juan Emilio Cheyre:

los cambios ocurridos en el escenario internacional, el advenimiento de gobiernos democráticos en el hemisferio y el fin de la Guerra Fría han creado condiciones propicias para afianzar la paz y seguridad en el hemisferio. Todo ello facilita las condiciones para que los Estados miembros de la OEA., continúen el necesario proceso de reflexión para eliminar los factores que generan desconfianza entre los Estados del hemisferio y para identificar nuevas modalidades de colaboración, a fin de consolidar la paz, asegurar el efectivo cumplimiento de los propósitos y principios de la carta de la OEA, garantizar el cumplimiento del derecho internacional y promover las relaciones de amistad y cooperación, todo lo cual redundará en el fortalecimiento de la seguridad en la región. (Cheyre, 2000, p. 35)

El mismo general Cheyre, plantea que uno de los elementos más importantes dentro de este nuevo ordenamiento de relaciones internacionales es la conformación de socios en torno a la seguridad:

La tendencia imperante demuestra que las relaciones de cooperación prevalecen sobre las de conflicto y de allí se desprende, como premisa básica, que la nueva arquitectura se orienta a la búsqueda de "asociaciones de seguridad"; concepto amplio en cuanto a 
sus componentes, ya no solamente restringidos a la variable militar - independiente de su indiscutible presencia - sino que también orientada hacia una efectiva búsqueda de solución de problemas de distinta índole, que al ser vencidos o aminorados propenden y fortalecen la viabilidad de integrarse a un esquema de cooperación. Una clara demostración es el hecho probado que, al menos en el Cono Sur de América, desde 1989 a 2000, la zona fue menos conflictiva que en otros períodos, dónde se privilegió la búsqueda de soluciones a los problemas, entre otros aspectos, debido a la integración y mutua dependencia económica. (Cheyre, 2002a, p. 36)

Con medidas de autoconfianza también se realiza disuasión porque los vecinos pueden percatarse de la capacidad que tienen los distintos cuerpos armados de un país. El concepto de las Medidas de Confianza Mutua fue introducido al interior del quehacer del Ejército chileno a partir de la gestión del general Juan Emilio Cheyre al mando de la Academia de Guerra, derivado de su entendimiento de un concepto generado en Europa. Para este general, la Academia de Guerra debía ser "un ente de pensamiento dentro del Ejército, que se abriera al diálogo cívico con los civiles lo cual fueron cuatro años muy intensos y allí se empezó a gestar todo un vínculo de Ejército con la civilidad" (Cheyre, Entrevista, 2012). En entrevista el general comentó los cambios en las FF.AA. y el rol de los militares en los nuevos contextos:

Los militares en política deben ser una excepción y esa excepción como en tanto cuanto excepción debe tener un término. Y en el término tiene que ser el ejército de la normalidad es un Ejército que está enmarcado en ser apolítico, no deliberante, jerarquizado, disciplinado, obediente al poder civil, estructurado, cumplidor de su quehacer militar, sin preferencias políticas, en fin eso en cuanto con la teoría en cuanto con la vida a mí me lo enseñó mi mujer. Por lo tanto no hay ningún invento mío y puedes verlo, como le digo, en Europa y en otras partes aplicado. (Cheyre, Entrevista, 2012)

\section{Profesionalismo militar participativo. Los avances institucionales para forjar el nuevo ejército chileno}

La Transición Democrática en Chile le demandó mayores niveles de profesionalismo a los uniformados, toda vez que la subordinación al poder civil era uno de los objetivos inconclusos a lo largo de los primeros doce años de democracia. Durante la comandancia en Jefe del general Cheyre, las condiciones del contexto local permitieron un avance en dicha dirección, logrando que la institución castrense iniciara un proceso de cambio doctrinario que ya hemos denominado como despinochetización.

Cuando comenzó Cheyre, el Ejército chileno se enfrentó a un contexto político diferente debido a que la figura del general Augusto Pinochet carecía de la relevancia que había tenido en el debate político nacional. Su imagen estaba vinculada a las violaciones a los derechos humanos cometidas durante el régimen militar, como consecuencia de su detención en Londres y los procesos judiciales en Chile. La figura del patriarca había pasado en un breve periodo de 
tiempo de ser reconocido como uno de los artífices de la democracia chilena, a la de genocida y dictador, procesado por crímenes de lesa humanidad, no sólo en nuestro país sino también en el extranjero. Fruto de esta situación y de la misión inconclusa del general Izurieta, el ejército seguía siendo percibido como una institución altamente ligada a la imagen de Pinochet, a pesar de que éste ya no fuera actor clave en la toma de decisiones a nivel institucional. Cheyre debía revitalizar el proceso de "normalización" de las relaciones cívico militares, además, la efectiva subordinación al poder civil, objetivo de la transición.

Desde el nombramiento de Cheyre por el presidente Ricardo Lagos el 19 de diciembre de 2001, se destacó el currículum del general, en tanto poseía los atributos que necesitaba el Ejército para comenzar un proceso de renovación y de legitimación. El oficialismo y la oposición se instaló en un consenso respecto a que la elección de Cheyre representaba un salto cualitativo hacia un nuevo Ejército.

Durante su cuatrienio, Cheyre emprendió los mayores cambios en función de la modernización del ejército. Entender los cambios a partir de un nuevo escenario internacional fue clave. La Ministra de Defensa, Michelle Bachelet, planteó que el periodo,

se caracterizó por un deterioro de la seguridad y estabilidad internacionales, especialmente fuera de los márgenes de nuestra región. Ésta, sin duda, fue una primera paradoja. Al finalizar la Guerra Fría se pensó que el mundo asistiría a mayores niveles de estabilidad y seguridad. Sin embargo, para que la estabilidad pudiera ser viable y plasmarse, a lo menos en ciertas regiones del mundo, fue necesario un duro período de reacomodación de naciones y entidades políticas. (Bachelet, 2003)

Cheyre, nos define este concepto, planteando que no se puede establecer y avanzar en este tipo de construcciones conceptuales si no existe un coherencia en el Alto Mando y una confianza entre los actores políticos y las instituciones armadas:

el profesionalismo militar participativo... se define como un quehacer en lo propio que son las dos primeras tareas y una actividad en aquellas cosas que sin desnaturalizar la función pueden ser realizadas por el Ejército. Y que de no ser realizadas, por una parte, se desaprovechan capacidades que se tienen tanto personales como de medios y por otra parte se resta a la sociedad de tener un apoyo en necesidades que tiene la sociedad y que pueden ser satisfechas si es que no se desnaturaliza la función militar. Yo allí voy entre lo que llamo yo dos límites: el militarismo, la actividad impropia de los militares que es la actividad política la actividad que sustituye al sector privado, la actividad que desnaturaliza la función. O el reduccionismo que le llamo yo que es también impropio, que es cuando le dicen militares a sus cuarteles y ustedes dedíquense solamente a la guerra y no se meta con la sociedad. Eso es mirar como una visión paria de la sociedad, en que no tiene nada que hacer, y usted dedíquese a esto u otro asunto. Se desaprovechan capacidades, se genera frustración. (Cheyre, Entrevista, 2012) 
Para que este concepto tenga asidero en las relaciones políticas y militares que establece la institución con las autoridades civiles, debe existir una fuerte subordinación al poder civil:

siempre subordinada al poder político y se llega botando las barreras de las desconfianzas, porque no se puede desarrollar un concepto así cuando usted por una parte tiene militares que pretendan ser políticos e invadir funciones que no les competen y por otra parte tenga a civiles que quieran tener a los militares como que no me hagan ruido porque me generan peligro a invadir campos que no son propios. (Cheyre, Entrevista, 2012)

En este sentido, la subordinación es una necesidad para establecer estos avances en la relación del Ejército con las autoridades civiles.

En este proceso, se constituyeron nuevos escenarios dentro de la política internacional que configuraron nuevas amenazas a los ejércitos del mundo, por lo que debieron redefinir sus profesionalismos al interior de sus instituciones. Así lo planteaba explícitamente el general Cheyre:

La identificación de los nuevos escenarios no es desviar, desnaturalizar o cambiar los componentes esenciales que dan sentido a la profesión militar... [significa] readecuar la estructura organizacional y la mentalidad de sus miembros en procura de responder a los nuevos requerimientos y responsabilidades. Existe una nueva época de transformaciones, de interdependencia y globalización, pérdida relativa de la centralidad del Estado en el monopolio de lo público. Nueva tendencia planetaria, problemas globales cuya solución depende de la cooperación de todos: calentamiento global, valoración por el respeto a la persona humana como sujeto del derecho internacional, condición que antes sólo se refería a los Estados. (Ejército de Chile, 2006)

Los cambios que afectaron el ordenamiento mundial de Posguerra Fría se relacionaron con los nuevos objetivos que debieron definirse para el Ejército. El cambio de mentalidad propuesto, apuntó hacia las nuevas funciones que tiene la institución, para impulsar al país a una integración en el escenario internacional, abandonando el ordenamiento y funcionamiento de la Guerra Fría. El mismo general planteó:

lo que si me corresponde es el cumplimiento cabal de mis obligaciones constitucionales y legales. Dentro de ellas la fundamental es responder, a través del ejercicio del Mando en Jefe del Ejército, a la necesidad de mantener y desarrollar una fuerza militar acorde con los requerimientos del Chile que transita los primeros años del siglo XXI, inserto en un mundo globalizado. Sin duda, el país lo hace con potencialidades ciertas para entrar al desarrollo pleno y con nuevos vínculos internacionales, que lo unen con importantes áreas del orbe. La seguridad y defensa no están fuera de una relación como la que se ha ido generando, donde nuestra nación se posiciona en este nuevo escenario mundial, caracterizado por la incertidumbre. Ello obliga a todo Estado a permanecer atento a las 
diversas señales y manifestaciones -externas o internas- que, si bien son interpretadas y oportunamente abordadas, le permitirá asegurarse un lugar estable en el frágil orden internacional actual. (Cheyre, 2002b, p.89)

La organización del Ejército buscó centrar sus avances en modernización acorde con los nuevos objetivos institucionales en función de los elementos de la política internacional del país y de la defensa. Los lineamientos de orientación del Ejército de Chile se relacionaron con el mantenimiento y consolidación de la paz y seguridad internacionales "mediante el empleo de sus capacidades disuasivas, las que resultan fundamentales para reducir las amenazas y minimizar el impacto de los riesgos presentes en el actual escenario internacional" (Ejército de Chile, 2006).

El Ejército definió las áreas de competencia de actuación estratégica, así:

Disuasión: convencer a los adversarios, que se formen la convicción, que la fuerza propia puede causarles un daño superior a los posibles beneficios que pueda tener una agresión a Chile. Se debe seguir construyendo un adecuado y eficaz instrumento de defensa, para la protección de sus ciudadanos. La disuasión es fundamental para mantener la paz y para disminuir las amenazas.

Cooperación internacional: objetivo subordinado a la disuasión. Las misiones de paz buscan elevar la estatura del país en el concierto internacional. Se obtiene como resultado de la participación chilena en este tipo de actividades una disuasión tangible y real.

Cooperación al desarrollo nacional: se materializa en diversas actividades que se relacionan con actividades propias de la función militar. Cuerpo militar del trabajo, auxilio y apoyo a la población civil.

Contribución a la unidad y cohesión nacional: El Ejército busca promover la confianza, la amistad cívica, la responsabilidad ciudadana, el cultivo del espíritu patrio y la conservación del patrimonio nacional. (Ejército de Chile, 2006. Negrillas en el texto original)

Estos cuatro ejes que articularon la política de modernizaciones del ejército, se centraron en los cambios que el contexto internacional y nacional les impuso a los soldados chilenos. Se redefinieron los planes de formación de oficiales cuyo propósito era incorporar cuatro áreas del conocimiento: Ciencias Humanas y Sociales, Ciencias Exactas y Naturales, Ciencias Militares y Desarrollo Físico. Con esta preparación se espera lograr un oficial con desarrollado en los niveles: moral, intelectual y físico (Ejército de Chile, 2006). La transformación de los planes de formación de oficiales se relacionó con la constatación de los nuevos objetivos para la realización de las actividades de los uniformados. El objetivo principal fue:

recoger los múltiples requerimientos de la época moderna y ofrecer a la sociedad y a la institución, un egresado con las competencias que le permitan asumir diferentes funciones en los más diversos ámbitos y llegar a ser un profesional proactivo, comprometido y respetuoso de los valores más arraigados del Ejército y defensor de la Patria. (Ejército de Chile, 2006) 
Se busca formar un soldado más civil. La vinculación del ejército con sus nuevas funciones y el escenario de la globalización en constante cambio e interdependiente, provocaron que desde la institución se hiciera una reformulación de los planes de estudio y formación de oficiales, para preparar a los nuevos soldados no sólo en los elementos propios de su experticia, sino que también en conocimiento más relacionados con el ámbito civil. Estas transformaciones buscaron la vinculación de la preparación de soldados con la variabilidad del ejército profesional, en el que se reconocieran los distintos escenarios en que los egresados pudieran intervenir, además, de generar cambios estructurales y de mentalidad al interior de la institución que permita:

Recoger en la formulación de su plan de estudios, las dinámicas demandas que se que se derivan de los avances tecnológicos de todo orden, reconociendo el carácter multidimensional de las ciencias militares... Luego de cuatro años de formación, este profesional se encuentra capacitado en lo moral, psicológico, intelectual y físico, para desempeñarse en el mando al nivel de Sección de Fusileros, ejerciendo en forma permanente el liderazgo en el rol de Comandante, educador y administrador de recursos humanos y materiales. (Ejército de Chile, 2006)

Las capacidades de los oficiales bajo las características de esta nueva formación les proporcionan mayores especialidades en función de las distintas tareas que pudieren realizar. Estas nuevas funciones parten de la constatación de distintos niveles de acción en el nuevo ejército y se relacionan con los cuatro ejes de su acción en la sociedad y la proyección internacional del país. Las tareas profesionales que debe cumplir un oficial de Ejército son:

Ejercicio del mando: ejercer el mando táctica y técnicamente al nivel de Sección de Fusileros, al mando administrativo de sus subordinados y desempeñar los cargos de guardia, emergencia, seguridad militar y servicios propios de su grado.

Educación e instrucción: instruir como combatiente individual al personal bajo su mando, procurando el mejor desarrollo en el orden moral, intelectual y físico, de acuerdo a metodologías de instrucción inherentes a su grado y competencias de comandante de Sección Fusileros.

Administración militar: administrar los cargos correspondientes a su nivel. Además, deberá ser capaz de desempeñarse como Jefe de una Comisión Administrativa de cargos internos y fiscales de una unidad táctica del ejército.

Perfeccionamiento y especialización: Mantener su capacidad profesional y cultural a través de los cursos de requisitos y especialización, valorando la educación permanente, a través del auto perfeccionamiento en áreas propias o complementarias, para lograr la eficiencia que requiere el cumplimiento de las funciones de cada nivel que le corresponda cumplir.

Integración a la comunidad: participar y comprometerse, asumiendo un rol proactivo y proyectivo en las diferentes actividades cívicas, culturales y sociales que sean requeridas por la institución y el país. (Ejército de Chile, 2006. Negrillas en el texto original)

Los objetivos que se impusieron los militares para dotar a los nuevos oficiales de una formación con una profunda formación científico cultural, que comprendiera los objetivos institucionales, 
significó acercar la preparación de los civiles a sus cuadros de oficiales. El proceso educativo de contó con importantes convenios en ciencias sociales, especialmente las políticas, en universidades de prestigio en el ámbito nacional, tales como, la Pontificia Universidad Católica de Chile, y la Universidad Diego Portales (Ejército de Chile, 2006). Cheyre destacó que el intercambio docente que se implementó con las universidades civiles, profundizó la capacidad de los soldados para comprender el mayormente su labor en la sociedad: "Hay que generar puertas para que la gente se incorpore a la vida civil. Y podremos mejorar el nivel de sueldos a través de una línea de carrera diferente, con una previsión menos cargada" (El Mercurio, 2004, $1^{\circ}$ de septiembre).

Durante el periodo al mando de Cheyre, la institución avanzó en el profesionalismo planteado por Morris Janowitz, es decir, un soldado con las capacidades intelectuales, no sólo de la experticia en las armas sino también en las temáticas civiles, como administración de recursos humanos, geopolítica, relaciones internacionales, economía, ciencias políticas, entre otras. Estas características fueron fruto del debate Posguerra Fría y absorbidas por el Ejército chileno.

Los nuevos oficiales del Ejército estarían bajo el nuevo concepto de "profesionalismo militar participativo" el cual se basa:

En la convicción de que la profesión militar no es sólo una actividad circunscrita exclusivamente al arte de mandar medios humanos y materiales y administrarlos racionalmente para la defensa de la Patria, pues quienes piensen de ese modo van a concluir inevitablemente que el carácter profesional del Ejército impone a los soldados la limitación de su actuar a lo estricta y técnicamente militar o que, tal vez en una metáfora exagerada, los soldados deben permanecer dentro de los cuarteles para realizar su cometido manteniendo operativa una reducida fuerza y sin participar en otras áreas de la vida nacional. (Este) Nuevo concepto propone ampliar las atribuciones de los integrantes del Ejército al desarrollo del país en otras áreas que implican la seguridad. Plantea la necesidad del punto medio, de equilibrio entre un protagonismo impropio y la exclusión de todo tipo de decisiones. (Ejército de Chile, 2006)

El nuevo concepto de profesionalismo destacó que los uniformados pueden ampliar sus funciones a todos los ámbitos de la seguridad nacional y la proyección de Chile dentro del escenario internacional. No obstante planteó que las instituciones armadas no deben ser utilizadas políticamente, porque eso no contribuye al desarrollo nacional y la cohesión social. Cheyre buscó bajo el concepto de profesionalismo que la institución se comprometiera en el proceso de "reconciliación nacional", Ilamando al resto de la sociedad chilena a evitar los odios y las venganzas.

Este concepto de profesionalismo incorporó el aporte del Ejército a la cohesión y unidad nacional, elemento que le permitió a su Comandante en Jefe realizar declaraciones en función de apurar el cierre por las investigaciones a las violaciones a los derechos humanos, entre 
otras. Sin embargo, los actos simbólicos que realizó el ejército en esa materia también fueron realizados bajo este concepto, como un aporte a lograr mayores niveles de legitimación social.

Uno de los elementos más importantes de este nuevo profesionalismo fue la cooperación internacional. Chile tiene una larga trayectoria de misiones de cooperación internacional, desde 1935, sin embargo el incremento de estas misiones ocurrió a partir de 1991 lo que demandó mayores niveles de participación de los militares nacionales en el despliegue de dichas fuerzas (Segura, 2010). No obstante, estas misiones se profundizaron a partir de la creación del Centro Conjunto para Operaciones de Paz de Chile (CECOPAC) creado en julio de 2002. Este centro, producto del proceso de modernización bajo el mando del general Cheyre, buscó implementar la preparación y el entrenamiento e un importante número de oficiales en el conocimiento de los procesos de planificación, evaluación y ejecución de las operaciones de paz. Este centro, brinda asesoría al Ministerio de Defensa en todas las materias requeridas para las misiones de paz.

Con esta base, se llevó a cabo en marzo de 2004 el despliegue de la misión de la Fuerza Multinacional Provisional para Haití. Con ello, el Ejército chileno logró en pocos días armar una delegación para que viajase a dicho país en misión de paz. Resulta trascendente este hito ya que los militares enviaron efectivos que habían recibido el entrenamiento necesario bajo el nuevo concepto de profesionalismo. El mismo general Cheyre planteó:

No se pueden improvisar intérpretes, no se pueden improvisar abogados expertos en derecho internacional, no se pueden improvisar fuerzas que hablen inglés en todos los niveles del mando. Se trata de una fuerza que nace de una planificación absolutamente acabada, seria, completa en todos sus puntos, de personal de inteligencia, de apoyo logístico y administrativos. (Ejército de Chile, 2004)

El énfasis de la máxima autoridad del Ejército en el despliegue de dicha misión, contagió a las autoridades civiles, pues en esta operación de paz en Haití se reflejaron de forma concreta los avances en materia de profesionalismo del Ejército y subordinación al poder civil, pues la decisión del envío de las tropas al país centroamericano recayó en la máxima autoridad civil. La ministra de Defensa de entonces Michelle Bachelet, destacó que:

es innegable que la decisión del Presidente de la República, respaldada por el Senado, de desplegar un contingente de 330 soldados del Ejército de Chile en la República de Haití, como parte de una fuerza multinacional mandatada por el Consejo de Seguridad de las Naciones Unidas para llevar paz al pueblo haitiano, ha tenido impacto tanto en la ciudadanía como en la opinión pública... creemos que la defensa es una materia de interés y responsabilidad nacional, y no sólo de algunos sectores, ni siquiera de sus Fuerzas Armadas exclusivamente, es necesario continuar trabajando para que todos los chilenos y chilenas puedan entender y apreciar las funciones profesionales que cumplen sus soldados y sentirlas como propias. (Bachelet, 2004) 
Con el despliegue de la Operación Paz en Haití, la legitimación del nuevo profesionalismo del Ejército se consolidó producto del impacto dentro de la sociedad civil que obtuvo esta misión que representó el más claro avance en materia de profesionalismo castrense. Así lo planteó el presidente Lagos que el Ejército chileno hace un sacrificio "por el bien de aquellos que, hoy día, están sufriendo una lucha desgarradora. Nuestro soldados van a luchar por la paz y no por la guerra" (Cooperativa, 2004, marzo 3). Agregando, "sólo enviamos a nuestros contingentes al exterior cuando hay una autoridad política establecida después de una crisis, a fin de ayudar a la recuperación de la paz y al restablecimiento de los canales institucionales y el ordenamiento general del país" (La Segunda, 2004, marzo 1). En síntesis, el Ejército de Chile, con la participación en las operaciones de paz en Haití, evidenció a la sociedad chilena los nuevos parámetros del profesionalismo. El General Juan Emilio Cheyre expresó:

La institución está permanentemente en condiciones de cumplir las misiones que se le encarguen, siempre con un afán de servicio. $Y$ hoy ese servicio de los ejércitos es para con su propia patria y también con una fuerte vocación por la paz del mundo. (El Mercurio, 2004, marzo 1)

En resumen, los cambios que se percibieron en el contexto global respecto del estudio de las relaciones cívico militares y la redefinición del profesionalismo castrense influyeron en el Ejército de Chile, quienes a partir de la constatación de nuevas amenazas y nuevas misiones, incorporaron nuevos elementos a la preparación de sus oficiales, logrando que el inicio de un proceso de cambio doctrinario en términos de su profesionalización.

\section{CONCLUSIÓN}

Los cambios en el escenario de la Post Guerra Fría provocaron cambios también a nivel de las definiciones de profesionalismo castrense y funciones de las Fuerzas Armadas en todo el mundo.

La constatación de nuevas amenazas produjo que el papel de las instituciones castrenses se redefiniera a partir de los nuevos objetivos para la articulación de las políticas de defensa.

En el caso chileno podemos plantear que el contexto en el que llega a la Comandancia en Jefe del Ejército Juan Emilio Cheyre, comenzó una transición doctrinaria que cambiaría la noción de la función militar en la sociedad chilena, complementando la tradición militar con elementos nuevos como la subordinación al poder civil, la cooperación internacional, la disuasión y el aporte para el desarrollo nacional y la cohesión social. Estos elementos, se reflejaron en las actuaciones institucionales del Ejército, principalmente al nuevo impulso a las misiones de paz.

Por último, entendemos que estos procesos de reinserción en las actividades multilaterales de cooperación y mantención de la paz le reportaron al Ejército de Chile mayores niveles de legitimación social, toda vez que sus actividades internacionales se tradujeron en una mayor valoración por parte de la sociedad chilena. 


\section{REFERENCIAS}

Bachelet, M. (2003). Clase Magistral: "Políticas Públicas y Defensa Nacional". Santiago: Universidad Tecnológica Metropolitana.

(2004). Clase Magistral de la Ministra de Defensa Nacional en la inauguración del año lectivo de las Academias de las Fuerzas Armadas. Santiago: Ministerio de Defensa.

Chile/Haití. (2004, marzo 1). El ejército chileno asegura estar "preparado" para enviar a Haití los 270 militares que prometió Lagos. El Mercurio. Recuperado de http://www.europapress. es/chance/gente/noticia-chile-haiti-ejercito-chileno-asegura-estar-preparado-enviar-haiti270-militares-prometio-lagos-20040301185230.html

Castells, M. (2006). Globalización, desarrollo y democracia: Chile en el contexto mundial. Santiago: Fondo de Cultura Económica.

Cheyre, J. (2000). Medidas de confianza mutua. Casos de América Latina y el Mediterráneo. . Santiago: Centro de Estudios e Investigaciones Militares.

(2002a). Componentes de una nueva arquitectura de seguridad en la región. FASOC. Revista Fuerzas Armadas y Sociedad. 17(3). 32-39.

(2002b). 2003: un desafío de futuro. FASOC. Revista de Fuerzas Armadas y Sociedad. 17(4). 89, 90.

(2012, enero 24). Entrevista. (F. S. Rojas, Entrevistador)

Comandos chilenos intervienen en Haití. (2004, marzo 2). La Nación. Recuperado de http:// www.lanacion.cl/comandos-chilenos-intervienen-en-haiti/noticias/2004-03-01/223729. html

Ejército de Chile. (2004). Especial Batallón Chile en Haití. Revista Armas y Servicios.

(2006). Ordenanza General del Ejército de Chile. Santiago: Ejército de Chile.

Gutiérrez, O. (2002). Sociología Militar. Santiago: Editorial Universitaria.

Hackett, J. (1983). The profesion of arms. New York: Mac Millan.

Huntington, S. (1995). El soldado y el Estado. Argentina: Grupo latinoamericano, Colección Estudios Públicos y Sociales. 
Janowitz, M. (1960). The Professional Soldier, A Social and Political Portrait. United States: Free Press.

Kuhlmann, J. \& Callaghan, J. (2004). Los militares y la sociedad en la Europa del siglo XXI: un análisis comparativo. Santiago: Ediciones Fundación Konrad Adenauer.

Lagos aseguró que el envío de tropas a Haití es "un sacrificio de todos". (2004, marzo 3). Cooperativa. Recuperado de http://www.cooperativa.cl/noticias/pais/relaciones-exteriores/ haiti/lagos-aseguro-que-el-envio-de-tropas-a-haiti-es-un-sacrificio-de-todos/2004-0303/142643.html

Lasswell, H. (1947). The analysis of political behavior. New York: Mac Millan.

Massardo, J. (2008). El ojo del cíclope: comentarios críticos a propósito del proceso de globalización. Santiago: Ariadna Ediciones.

Oehling, H. (1977). La función política del Ejército. Madrid: Institutos de Estudios Políticos.

Rojo, G. (2006). Globalización e identidades nacionales y postnacionales ¿de qué estamos hablando? Santiago: Ediciones LOM.

Romero, E. (1962). Temas de Moral Militar. Madrid: Ministerio de Marina.

Segura, V. (2010). Chile en el marco de la cooperación internacional: Siete décadas en operaciones de paz. ANEPE Política y Estrategia. 115. 122-140. 